Original Research Report

\title{
The Relationship between Patient Motivations with Dietary Compliance in Patients Diabetes Mellitus at Haruai Health Center
}

\author{
Anjar Padmi Pratiwi ${ }^{1}$, Muhammad Riduansyah ${ }^{1}$, Eirene E. M. Gaghauna ${ }^{1}$ \\ ${ }^{1}$ Emercency Nursing Departement, Nursing Program, Faculty of Health, Sari Mulia \\ University. Banjarmasin, Indonesia.
}

\begin{abstract}
Article History
Received:

29.07.2021

Revised:

19.08.2021

Accepted:

04.09 .2021

*Corresponding Author:

Muhammad Riduansyah

Email:

riduan21.mr@gmail.com
\end{abstract}

This is an open access article, licensed under: $\mathrm{CC}-\mathrm{BY}-\mathrm{SA}$

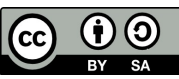

Abstract: One of the risk factors that affect the increase in blood sugar levels in diabetes mellitus is an irregular diet. To prevent this, it is necessary to comply with the diet. In order for patients to comply with diet therapy, selfmotivation and external motivation are needed. To determine patient motivation, level of dietary compliance and the correlation between patient motivation and dietary compliance in diabetes mellitus patients at community Haruai. This study used a cross sectional approach. The sample technique was taken $25 \%$ of the total population by purposive sampling method, the sample size was 43. The results of this study indicated based on Sperman Rank (Rho) analysis there was a correlation between patient motivation and dietary compliance in diabetes mellitus patients at community Health Center Haruai with a $\mathrm{p}$ value of 0,000 . There is a positive correlation between motivation and dietary compliance in diabetes mellitus patients, which means that the better the motivation of the patient, the better the dietary compliance is in the diabetes mellitus patient and both have a strong correlation.

Keywords: Diabetes Mellitus, Diet Compliance, Motivation. 


\section{Introduction}

Diabetes mellitus is a chronic metabolic disorder caused by the pancreas not producing enough insulin or the body cannot use the insulin it produces effectively [1]. Based on the latest data published in the IDF Diabetes Atlas 9th year 2019 shows that 463 million adults currently have diabetes. Without sufficient action to tackle this pandemic, 578 million people will have diabetes by 2030 . That number will jump to 700 million in 2045. In 2017 it was known that diabetes mellitus in Indonesia was still increasing.

Indonesia is ranked the sixth largest in the world with 10.3 million diabetes mellitus patients aged 20-79 years. This is in line with the Basic Health Research which shows an increase in the number of diabetes mellitus, with a percentage of $6.9 \%$ in 2013 and $8.5 \%$ in 2018 [2]. Based on data from the South Kalimantan Provincial Health Office in 2017, diabetes mellitus was ranked 2nd and there were 10,875 patients [3]. In 2019 the prevalence of diabetes mellitus in South Kalimantan was estimated at $38,113(1.4 \%)$ of the total population aged $>14$ years [4].

Based on a preliminary study conducted by researchers in June 2020, data obtained from the medical records of the Haruai Health Center, Tabalong Regency, namely, there were 196 patients with diabetes mellitus in 2017, 241 patients in 2018, and lastly in 2019 the number of patients with diabetes mellitus was 329 cases. Researchers conducted a question and answer session with 20 diabetes mellitus patients at the Haruai Health Center, 12 of whom said they were not obedient in carrying out their diet, their daily meals were not well controlled.

Several risk factors that influence the increase in the incidence of diabetes mellitus include lifestyle, obesity, irregular eating patterns and lack of physical activity. Irregular eating patterns are one of the main cause's diabetes mellitus [5]. According to research conducted by Nur Isnaini and Muhammad Agung Helmi Saputra in 2017, things that can be done to prevent complications in diabetes mellitus patients include medication (pharmacological therapy), diet therapy, and exercise. The main thing that is done to prevent complications for diabetic patients is adherence to diet therapy [6]. Patient compliance with diet therapy is one of the obstacles experienced by patients with diabetes mellitus [5].

\section{Literature Review}

Diabetes Mellitus is a chronic disorder of blood sugar metabolism, characterized by high blood sugar levels caused by impaired insulin secretion, insulin resistance or both [7].

Diet according is adjusting the amount of food and eating time with the body's ability to process it, mixing and matching types of food so that it has more value in an effort to cure a disease, and modifying processing techniques so that the dish can be enjoyed without risking other health effects [8].

The general goal of treatment for diabetes mellitus is to control blood sugar levels and improve the patient's quality of life. One of them is by setting the food menu or diet. According to Sutanto, the principle of preparing a diet for diabetic's aims to adjust the body's ability to use food so that it helps lower blood sugar levels to near normal, lowers sugar in urine to negative, and achieves normal or ideal weight [9].

One of the management of diabetes mellitus is a balanced diet. Constraints in handling diabetes mellitus diet are patient saturation following diet therapy and lack of family support [8]. Other sources say the recommended foods for diabetics include skinless chicken, fish, egg whites, lean meats. The recommended sources of vegetable protein include tempeh, tofu, green beans, kidney beans, peanuts, soybeans, vegetables that are allowed including kale, peanut leaves, oyong, cucumber, tomatoes, water squash, cauliflower, radishes, mustard greens, lettuce, celery, and eggplant. Fruits such as oranges, apples, papaya, guava, salak and star fruit are allowed to be consumed [10].

Motivation according to Eza Setia Cahyo Utomo is something that encourages someone to do something [11]. Motivation is human behavior that arises because of a need that drives action towards a certain goal. It further explains that motivation appears in 2 basic forms, namely extrinsic motivation and intrinsic motivation. Extrinsic motivation is what you do to other people to motivate, while intrinsic motivation are factors from within that influence people to behave or to move in a certain direction [12].

Patient compliance is patient behavior that is in accordance with the provisions given by health professionals [13]. According to Nuning Rahayu, one's compliance is influenced by the following factors, including [14]: 
(1) Intrinsic factor: Motivation, Belief, attitude and personality, Education and Understanding of instructions.

(2) Extrinsic factors: Social support, Support from healthcare professionals, Quality of interaction, Change of therapy model model.

\section{Method}

This research uses correlational research and correlation analysis with cross sectional approach. This research was conducted on 3 - 23 December 2020 at the Haruai Health Center. The sample in this study were 43 patients with diabetes mellitus who were registered at the Haruai Public Health Center. In this study, researchers used quantitative data in the form of ordinal data for both motivation and compliance data for diabetes mellitus patients.

The technique used by researchers in obtaining primary data is by distributing questionnaires and direct questions and answers to diabetes mellitus patients who seek treatment at the Haruai Health Center. Researchers used a diabetes mellitus diet motivation questionnaire, namely the Treatment Self-Regulation Questionnaire (TSRQ) questionnaire used by Zycinka et al in 2012, then used and modified again by Susanti in 2019 which has been tested for validity and reliability [15].

The dietary compliance questionnaire used by the researcher is a questionnaire that has been tested for validity and reliability by [15] which contains compliance in carrying out the eating schedule, being obedient in choosing the type of food, being obedient in measuring the amount of food, being obedient in maintaining weight and being obedient to follow the treatment program. The data were analyzed using the SPSS application on a computer using the Sperman Rank (Rho) test then the research data were presented in the form of tables and narratives [16].

\section{Result and Discussion}

\subsection{Sample Characteristics}

The description of gender characteristics in the Haruai Health Center is mostly female, 27 people $(62.8 \%)$ patients. In the age group, most of the elderly are $46-65$ years as many as 28 people $(76.7 \%)$. Patients suffering from diabetes mellitus mostly 5 years as many as 33 people $(76.7 \%)$

Table 1. Characteristics of the sample at the Haruai Health Center

\begin{tabular}{lccc}
\hline \multicolumn{1}{c}{ Patient Characteristics } & Specific Variables & Frequency & Percentage \\
\hline \multirow{2}{*}{ Gender } & Male & 16 & 37.2 \\
\cline { 2 - 4 } & Famale & 27 & 62.8 \\
\hline \multirow{2}{*}{ Age } & Adult (26-45 years) & 15 & 34,9 \\
\cline { 2 - 4 } & Elderly (46-65 years) & 28 & 65,1 \\
\hline \multirow{2}{*}{$\begin{array}{l}\text { Long time suffering from } \\
\text { diabetes mellitus }\end{array}$} & $\leq 5$ Years & 33 & 76,7 \\
\cline { 2 - 4 } Motivation & $>5$ Years & 10 & 23,3 \\
\cline { 2 - 4 } & Good & 17 & 39,5 \\
\cline { 2 - 4 } Diet & Not good & 26 & 60,5 \\
\cline { 2 - 4 } & Good & 10 & 60,5 \\
\cline { 2 - 4 } & Enough & 7 & 16,3 \\
\hline
\end{tabular}

In the study, the description of the motivation of diabetes mellitus patients consists of 2 categories, namely good motivation and poor motivation. The data on the motivation of diabetes mellitus patients at the Haruai Health Center was the highest as much as $60.5 \%$ had poor motivation and $39.5 \%$ of patients had good motivation. The level of dietary compliance in patients with diabetes mellitus 
consists of 3 categories, namely good, sufficient and bad. The data obtained on the level of dietary compliance in patients with diabetes mellitus at the Haruai Health Center is the highest at the level of compliance which is sufficient $60.5 \%$ and as many as $16.3 \%$ of patients are at the level of compliance, poor compliance.

Based on Table 1, it can be seen that the data related to the characteristics of the sample at the Haruai Health Center were the gender, age, long time suffering from diabetes mellitus, motivation and diet patients.

Tabel 2 show the relationship between patient motivation and dietary compliance in patients with diabetes mellitus at the Haruai Health Center.

Tabel 2. The Relationship between Patient Motivation and Dietary Compliance

\begin{tabular}{|c|c|c|c|c|c|c|c|c|}
\hline \multirow{3}{*}{ Kategori Motivasi } & \multicolumn{6}{|c|}{ Diet Compliance Rate } & \multirow{2}{*}{\multicolumn{2}{|c|}{ Total }} \\
\hline & \multicolumn{2}{|c|}{ Good } & \multicolumn{2}{|c|}{ Enough } & \multicolumn{2}{|c|}{$\mathrm{Bad}$} & & \\
\hline & $\mathrm{n}$ & $\%$ & $\mathrm{n}$ & $\%$ & $\mathrm{n}$ & $\%$ & $\mathrm{n}$ & $\%$ \\
\hline Good & 10 & 58,9 & 6 & 35,2 & 1 & 5,9 & 17 & 100 \\
\hline Not good & 0 & 0 & 20 & 76,9 & 6 & 23,1 & 26 & 100 \\
\hline Jumlah & 10 & 58,9 & 26 & 112,1 & 7 & 29 & & \\
\hline Sperman rank test results & \multicolumn{8}{|c|}{$p$ value $=0,000$, correlation coefficient $=0,606$} \\
\hline
\end{tabular}

Sperman rank test analysis obtained $\mathrm{p}$ value $0.000<0.01$, which means that there is a significant relationship between patient motivation and dietary compliance in patients with diabetes mellitus at the Haruai Health Center. In addition to the $p$ value, a correlation coefficient of 0.606 is also obtained, which means that the relationship between the two variables has a strong strength or closeness.

The value of the correlation coefficient is also positive, which means that the motivation and dietary compliance variables are unidirectional, it states that the better the patient's motivation, the better the diet compliance of the diabetes mellitus patient and vice versa if the patient's motivation is not good, the patient's compliance can decrease to a lower level.

\subsection{Motivation in Patients with Diabetes Mellitus at The Haruai Health Center}

Based on research data that has been carried out by researchers in December 2020 regarding motivation in diabetes mellitus patients at the Haruai Health Center, the results showed that from 43 patients it was seen that the highest majority of patients were in the category of poor motivation, namely $60.5 \%$ and $39.5 \%$ of patients have good motivation.

In addition, researchers also conducted an analysis of motivation questionnaires, from the analysis it was found that the highest motivational aspect in influencing patient motivation was the aspect of obtaining better health.Both the patients who had good motivation and those who were not well motivated answered that they strongly agreed and agreed to regulate their diet, and that managing their diet was a good thing for their health and was one of the important things for their lives. Only a small proportion still answered strongly disagree with disagreeing in maintaining their diet. This is supported by the theory which says that good or bad motivation that arises in a person can be due to the desire of oneself to do something without any outside influence or because of encouragement that comes from outside the individual and cannot be controlled by the individual [14].

Research conducted explains that good or bad motivation can be due to psychological processes that reflect the interaction between attitudes, perception needs and decisions that occur in an individual and motivation arises as a result of internal and external factors [14].

\subsection{Level of Dietary Compliance in Patients with Diabetes Mellitus at the Haruai Health Center}

Based on research data that has been carried out by researchers in December 2020 regarding dietary compliance in diabetes mellitus patients at the Haruai Health Center, the results were that the majority 
of patients or $60.5 \%$ were in the category of adequate dietary compliance level, followed by $23.2 \%$ of patients were at the level of good dietary adherence, and $16.3 \%$ of patients were at the level of poor dietary adherence. From these data it can be seen that patients who have a sufficient level of compliance in carrying out a diabetes mellitus diet are very high, this is because there is still hope from patients to improve their health levels.

Researchers also conducted a questionnaire analysis of dietary compliance in patients with diabetes mellitus, from the analysis it was found that the highest aspect of compliance carried out by patients was the obedient aspect in participating in health programs. In patients who have good compliance and sufficient compliance they answer always and often eat as recommended by health workers, routinely check blood sugar levels at the health services, and use sugar specifically for diabetes for sweet foods or drinks, only a small proportion have poor compliance, they answer that they do not want to and rarely follow the advice of doctors or other health workers because the diabetes mellitus diet is difficult, they rarely check their blood sugar levels and never use sugar specifically for diabetes in the sweet foods or drinks they consume. As it is known that diabetes management is very dependent on the compliance of the patient himself. Compliance is behavior that is carried out in accordance with the recommendations of health workers to their patients [15].

So before that, the patient needs to understand the importance and principles of a diet that is appropriate to his condition and carry out regular check-ups to health facilities to find out if there are developments towards disease complications [15]. By being obedient to diabetes mellitus patients in carrying out a diet, they can make their weight normal, normalize blood pressure values, and reduce blood sugar [16].

A person's adherence to a diet is influenced by the following factors such as motivation, education, understanding of the instructions given, beliefs, attitudes and personality of a person, social support, support from health workers who care for both doctors, nurses and nutritionists, interaction with others environment [17]. This is in line with the research conducted by [6] namely the patient's compliance in maintaining his diet due to the support or desire of the patient himself in order to maintain his health condition.

\subsection{The Relationship between Patient Motivation and Dietary Compliance in Patients with Diabetes Mellitus at the Haruai Health Center}

Data from the results of the study were tested using the sperman rank test, obtained $p$ value $0.000<$ 0.01 which means there is a significant relationship between patient motivation and dietary compliance in diabetes mellitus patients at the Haruai Health Center. In addition to the $p$ value, a positive correlation coefficient is also obtained, namely 0.606 where the motivation and dietary compliance variables are unidirectional, meaning that the better the patient's motivation, the better the diet compliance in the diabetes mellitus patient and both have a strong relationship.

The results of this study are supported by the theory which states that the factors that influence one's dietary adherence are motivation [17]. Motivation is a determinant of compliance in the implementation of therapy and blood sugar control in patients with diabetes mellitus [17]. The higher the patient's motivation, the greater the opportunity to adhere to the recommended diet [18]. This is in accordance with a study conducted by Bartalina in 2016 which found a relationship between motivation and dietary compliance in patients with diabetes mellitus, the study stated that the patient's motivation was one of the factors that influenced him to undergo a diabetes mellitus diet. The better the patient's motivation, the higher the level of compliance. Conversely, if the patient's motivation is low, the level of compliance in carrying out the diabetes mellitus diet also decreases.

Stated that patients who have good motivation and high compliance feel better because blood sugar is continuously controlled, they adhere to the diet because they get motivational encouragement from outside such as family and health workers, on the other hand patients who have less motivation and poor compliance say their motivation decreases because they feel they have been sick with diabetes mellitus for a long time which results in their compliance in running a diet to be disobedient [19].

The results of the researcher's research are also in line with research conducted [8] which said there was a significant relationship between self-motivation and adherence to a diabetes mellitus diet in outpatient type II diabetes mellitus patients at Karanganyar Hospital. This study states that patients with diabetes mellitus who have good self-motivation have the opportunity to adhere to their diet compared to patients whose motivation is not good. This is because patients who have good 
motivation have confidence in themselves that they are able to carry out certain tasks or actions, with the stimulation of the stimulus in the form of family, environmental and social support will form expectations which then affect the patient's motivation to behave such as maintaining their health obediently in running a diet and is continuous [8].

Research that also supports that there is a relationship between motivation and dietary compliance in diabetes mellitus patients was put forward by [5].

\section{Conclusion}

In his research said that encouragement and motivation are very important roles because motivation contains behavior based on the patient's desire to recover and reduce the risk of complications that can occur in patients with diabetes mellitus

\section{References}

[1] Infodatin (Data and Information Center of the Indonesian Ministry of Health), "Diabetes Situation and Analysis," Indonesian Ministry of Health, 2014. [Online]. Available: https://www.kemkes.go.id. [Accessed: July. 17, 2021].

[2] Ministry of Health of the Republic of Indonesia, "Main Results of Riskesdas: Basic Health Research," Indonesian Ministry of Health, 2018. [Online]. Available: https://www.kemkes.go.id. [Accessed: July. 17, 2021].

[3] Ardianti, Tri and Z. Fitri. "The Relationship of Knowledge and Dietary Compliance with Blood Sugar Levels in Diabetes Mellitus Patients at the Internal Medicine Polyclinic of Idaman Hospital Banjarbaru 2018," Jurkessia, vol. 9, no. 2, pp. 24-32, 2019.

[4] A. R. Meldy, "Relationship of Patient Knowledge and Behavior on Diabetes Mellitus Management in Banjarbaru, South Kalimantan," Nusantara Medical Science Journal. 2019 [Online]. Available: https:// 10.20956/nmsj.v4il.5955. [Accessed: July. 17, 2021].

[5] Kusumayanti, Erma and B. Rahayu. "The Relationship of Self-Motivation and Support of Health Workers with Diet Compliance of Type 2 DM patients in the UPTD Work Area of the Banjarbaru," Jurkessia, vol. 8, no. 4, pp. 56-67, 2019.

[6] N. Isnaini, and M. A. Saputra, "Knowledge and Motivation to Improve Diet Compliance of Type II Diabetes Mellitus Patients," Scientific Journal of Health Sciences, vol. 15, no 3, 2017.

[7] E. K. Lufthiani and N. F Sitepu, Counseling Guidelines in Diabetes Mellitus Prevention Efforts. Yogyakarta: Depublish, 2020.

[8] K. N. Risti, "The Relationship between Self-Motivation and Nutritional Knowledge on DM Dietary Compliance in Outpatient Diabetes Mellitus Type II Patients at Karanganyar Hospital," Journal of Health. Vol. 10, no. 2, 2017.

[9] Krisnatuti, Yenrina, and Dini Rasjmida. Healthy Diet for Diabetes Mellitus Patients. Jakarta: Self-Help Publisher, 2014.

[10] A. Sugiarto, "Diabetes Mellitus Diet," Ahli Gizi, 2017 [Online]. Available: [Internet]. Available at: https://ahligizi.id/article/detailarticle/3/terbaru_terpop/Diet-Diabetes-Mellitus. [Accessed: June.6, 2020].

[11] E. S. C. Utomo, Memorize! Thoughts and Motivation for Memorizing His Words. Jakarta: Guepedia, 2019.

[12] S. Bahri and F. Zamzam, Quantitative Research Model Based on SEM-Amos. Yogyakarta: Depublish, 2015.

[13] R. N. Kumala, "The Relationship of Nurse Therapeutic Communication with Dietary Compliance in Diabetes Mellitus Patients (Study at Internal Medicine Poly Hospital Jombang)". Jombang: College of Health Sciences, 2018.

[14] W. S. Ramadhani, "Hubungan Pengetahuan Diet Dan Motivasi Diri Dengan Kepatuhan Diet Pada Remaja Penyandang Diabetes Melitus di Surabaya," Jurnal Mahasiswa UNESA, Vol. 8, No. 2, 2019.

[15] R. D. Susanti, "The Relationship of Motivation and Health Locus of Control with Dietary Compliance in Diabetes Mellitus Patients". Surabaya: Airlangga University Library, 2018.

[16] Supriyadi. Practical Guide to Diabetes Mellitus Foot Screening. Yogyakarta: Depublish, 2017. 
[17] Prasetya, Fikki, Jumakil, N. M. Sidiq, Proceedings of the National Health Seminar on Health Service Strengthening and Innovation in the Industrial Revolution Era. Kendari: UHO EduPress, 2019.

[18] M. M. Runtuwene and M. Katuuk, "The Relationship of Intrinsic Motivation with Diet Compliance of Type II Diabetes Mellitus Patients at Ranotana Weru Health Center." Nursing ejournal. vol. 7, no. 1, 2019.

[19] Bartalina and Purnama, "The Relationship of Length of Illness, Knowledge, Patient Motivation and Family Support with Diet Compliance of Diabetes Mellitus Patients," Journal of Health. vol. 8, no. 2, pp. 329-340, 2016.

[20] A. A. Hidayat, Nursing Research Methods and Data Analysis Techniques. Jakarta: Salemba Medika. 2011. 